\title{
Dose Dependency and Individual Variability of the Lipopolysaccharide- Induced Bovine Acute Phase Protein Response
}

\author{
S. Jacobsen, ${ }^{1}$ P. H. Andersen, ${ }^{1}$ T. Toelboell, ${ }^{1}$ and P. M. H. Heegaard ${ }^{2}$ \\ ${ }^{1}$ Department of Clinical Studies, \\ Royal Veterinary and Agricultural University, \\ Copenhagen, Denmark \\ 2Department of Immunology and Biochemistry, \\ Danish Veterinary Institute, Copenhagen, Denmark
}

\section{ABSTRACT}

In order to investigate the dose dependency and the individual variability of the lipopolysaccharide (LPS)induced acute phase protein response in cattle, 8 nonlactating, nonpregnant Danish Holstein cows were challenged 3 times each by intravenous injection of increasing doses (10, 100, and $1000 \mathrm{ng} / \mathrm{kg}$, consecutively) of Escherichia coli LPS with 3-wk intervals. All 3 LPS doses resulted in a rapid increase in serum concentrations of haptoglobin and serum amyloid A (SAA) and a decrease in serum concentrations of albumin in all 8 cows. Serum concentrations of acute phase proteins (APP) remained altered for several days after each LPS injection, and their increase or decrease was significantly related to LPS dose. In addition to dose dependency, the response was also dependent on the individual, as APP concentrations differed significantly among cows. To compare APP production in 2 consecutive challenges, individual APP levels after the challenge with $100 \mathrm{ng}$ LPS/kg were correlated to levels attained after the challenge with $1000 \mathrm{ng}$ LPS/kg. Serum amyloid A concentrations correlated between the 2 challenges, whereas haptoglobin concentrations tended to correlate; no correlation could be demonstrated between SAA and haptoglobin concentrations in either of the challenges, which suggests that the synthesis of haptoglobin and SAA are regulated in different ways. In conclusion, cattle are highly susceptible to LPS, as very low doses of LPS elicited acute phase albumin, SAA, and haptoglobin responses. Concentrations of APP not only reflect the magnitude of LPS exposure but are also influenced by the ability of the individual cow to mount an acute phase response. The ability to produce SAA and haptoglobin may be an innate characteristic of the individual, as responses in consecutive challenges were quantitatively similar.

Received January 27, 2004.

Accepted May 25, 2004.

Corresponding author: S. Jacobsen; e-mail: stj@kvl.dk.
(Key words: lipopolysaccharide, serum amyloid A, haptoglobin, individual variation)

Abbreviation key: APP = acute phase protein $(\mathrm{s})$, $\mathbf{A U C}=$ area(s) under the curve, $\mathbf{S A A}=$ serum amyloid A, $\mathbf{T N F}=$ tumor necrosis factor.

\section{INTRODUCTION}

Systemic exposure to LPS has been linked to a number of common diseases in the bovine, for example, coliform mastitis, neonatal coliform septicemia, ruminal acidosis, laminitis, and displaced abomasum (Boosman et al., 1991; Andersen, 1994; Blum et al., 2000). Previous studies have noted that the ability to withstand LPS exposure or Gram-negative infection varies considerably between individuals (Michaels et al., 1988; Deignan et al., 2000) and that this ability seems to be an innate characteristic of the individual cow (Hirvonen et al., 1999).

In mice, the outcome of Gram-negative infection has been shown to correlate with the capacity to mount an acute inflammatory response (Araujo et al., 1998), and in models of bovine Escherichia coli mastitis, the severity of the clinical course of infection has been linked to the individual's capacity to elicit an acute inflammatory response, for example, secretion of tumor necrosis factor (TNF) $\alpha$ (Sordillo et al., 1992) or induction of respiratory burst and chemotactic activity of polymorphonuclear leukocytes (Lohuis et al., 1990; Vandeputte-van Messom et al., 1993).

Lipopolysaccharides and infections with Gram-negative bacteria are known to be potent inducers of inflammation and the acute phase response, giving rise to large changes in the serum concentrations of acute phase proteins (APP) such as haptoglobin, serum amyloid A (SAA), and albumin (Boosman et al., 1989; Werling et al., 1996). The main functions of haptoglobin and SAA in the acute phase response are only known in part, but the facts that APP are highly conserved during evolution and that their serum levels change dramatically in response to a wide variety of harmful 
stimuli (infection, tissue injury, aseptic inflammation, cancer, etc.) suggest important roles for them in the modulation of inflammatory reactions. An individual's ability to raise an acute phase response may therefore play a role in its capacity to withstand systemic exposure to LPS. However, individual differences in the APP response in cattle have never been investigated.

The aim of the present study was to characterize the dose dependency of the LPS-induced APP response and to investigate to what extent it differs between individual cows. Eight dairy cows were each challenged 3 times by intravenous injection of low doses of LPS, and serum concentrations of haptoglobin, SAA, and albumin were measured for $144 \mathrm{~h}$ after each injection.

\section{MATERIALS AND METHODS}

\section{Animals and Experimental Procedures}

Eight clinically healthy, nonpregnant, nonlactating Danish Holstein cows (cows I to VIII) of first to fifth parity and weighing (mean $\pm \mathrm{SD}$ ) $603 \pm 59 \mathrm{~kg}$ were included in the study. They were stabled in tie stalls and fed grass silage, hay, and water ad libitum for 4 wk before and throughout the experiment. The cows were accustomed to being handled and all experimental procedures during the 4-wk acclimatization period, and the experiment was carried out according to the Danish animal experimentation law.

On arrival, clinical examinations of udder, uterus, and limbs were performed, and cows IV and VII were subsequently treated with intramammary antibiotics. During the experimental period, clinical examinations of udder, limbs, and ears were performed daily. Mild periphlebitis of the auricular vein was diagnosed in cow VII at $\mathrm{h} 96,120$, and 144 of the $10 \mathrm{ng}$ LPS/kg challenge. This was treated topically and healed in $1 \mathrm{wk}$. Cow IV was treated for mastitis at h 120 and 144 of the 1000 ng LPS/kg challenge.

One week before each challenge, cows were equipped with indwelling venous catheters (Secalon Seldy, Becton Dickinson, Brøndby, Denmark). These were inserted into one of the larger ear veins (v. auricularis intermedia or $\mathrm{v}$. auricularis medialis) and passed through v. auricularis caudalis into $\mathrm{v}$. jugularis externa. At each blood sampling, and at least once daily, the ears were examined for inflammatory reactions, and catheters were flushed with approximately $15 \mathrm{~mL}$ of $0.9 \%$ sterile saline. Deposition of $1 \mathrm{~mL}$ of $0.9 \%$ sterile saline containing 50 IU of heparin (Løvens Kemiske Fabrik, Ballerup, Denmark) prevented clot formation. Before flushing or blood collection, the heparinized saline solution was aspirated along with approximately $5 \mathrm{~mL}$ of blood and discarded.
The cows were challenged 3 times with 3 -wk intervals using 10, 100, and $1000 \mathrm{ng}$ LPS/kg, consecutively ( $E$. coli strain O55:B5, Westphal's extraction, Sigma Chemical Co., St. Louis, MO). In each challenge, LPS was injected intravenously at $0 \mathrm{~h}$ through the indwelling venous catheter.

Blood was collected in 30-mL single-use syringes (B. Braun Melsungen, Melsungen, Germany) and immediately transferred to vacutainer tubes (Becton Dickinson, Vacutainer System, Brøndby, Denmark). Blood for determination of haptoglobin, SAA, and albumin concentrations was collected at $-144,0,12,24,36,48,72$, 94,120 , and $144 \mathrm{~h}$ after the challenge. In addition to these time points, SAA was also determined in blood samples obtained at $6 \mathrm{~h}$ after the challenge, and albumin was also determined at $0.5,1,2,3,4,5$, and $6 \mathrm{~h}$ after the challenge. A standardized clinical examination was carried out at each sampling.

Serum samples were prepared by letting the blood samples clot at room temperature for $18 \mathrm{~h}$ before centrifugation at $2500 \times g$ and separation of serum. The serum samples were stored at $-18^{\circ} \mathrm{C}$ until analysis.

\section{Laboratory Analyses}

The concentrations of SAA in the serum samples were determined in a commercially available sandwich ELISA (Tridelta Development Ltd., Greystones Co., Wicklow, Ireland) according to the manufacturer's instructions. The monoclonal antibodies and the ELISA were originally described by McDonald et al. (1991). All samples including the standards were tested in duplicate. Samples were initially diluted 1:500, and samples with optical density values above the range of the standard curve were diluted further and reanalyzed. Optical density values were read on an automatic plate reader (model 550, Bio-Rad, Hercules, CA) at $450 \mathrm{~nm}$ with reference at $595 \mathrm{~nm}$. According to the manufacturer, the detection limit of the assay was $0.3 \mu \mathrm{g} / \mathrm{mL}$.

Serum haptoglobin concentrations were determined in a sandwich ELISA originally described by Godson et al. (1996) as described previously (Heegaard et al., 2000) using a pool of bovine serum as standard. The bovine serum standard was calibrated against a standard obtained from a European Union concerted action on standardization of animal APP (QLK5-CT-199901532). The lower detection limit of the assay, as defined by the linear range of the standard curve, was 0.5 $\mu \mathrm{g} / \mathrm{mL}$. The samples were tested in serial dilutions of 1:100, 1:300, and 1:900, resulting in a lower limit of detection of $50 \mu \mathrm{g}$ haptoglobin/mL.

Serum albumin concentrations were determined by bromocresol green-binding and spectrophotometrical 
determination at $596 \mathrm{~nm}$ (ADVIA 1650, Bayer A/S, Lyngby, Denmark).

\section{Statistical Analyses}

The statistical analyses were performed as a repeated measures ANOVA using the PROC MIXED procedure of SAS (1999). The explanatory variables LPS dose, time (h after the challenge), cow identity, and the interaction between LPS dose and time were included in the model as fixed effects. The correlation structure between repeated measurements for each cow within each dose was modeled by a spatial power structure to allow for the unequal sampling intervals. The outcome variables were haptoglobin, SAA, and albumin concentrations in serum, and the ratio between haptoglobin and SAA concentrations. Assumptions were verified on residual plots and tested for normality. Serum amyloid A concentrations were logarithmically transformed to obtain normally distributed and unskewed residuals as assumed.

Differences in least squares means estimates from the repeated measurement analyses were used to identify time points or intervals at which the respective responses to 10,100 , and $1000 \mathrm{ng} \mathrm{LPS} / \mathrm{kg}$ differed significantly and to identify significant increases from the prechallenge baseline values. Bonferroni's multiple comparison procedure was used in order to control Type I errors. If not otherwise stated, a 5\% level of significance was used.

Differences in residuals between the statistical model described above and a model where the variable cow identity was left out were used to estimate the amount of variation in APP concentrations explained by this variable.

Areas under the curve (AUC) were calculated for each cow as:

$$
\mathrm{AUC}=\Sigma\left[\left(t_{i}-t_{i-1}\right) f_{i-1}\right]+\left[0.5\left(t_{i}-t_{i-1}\right)\left(f_{i}-f_{i-1}\right)\right],
$$

where $t_{i}=$ time of observation, $t_{i-1}=$ previous time of observation, $f_{i}=$ SAA or haptoglobin concentrations at time $i$, and $f_{i-1}=$ SAA or haptoglobin concentrations at time $i-1$. Areas under the curve were used as a summary measure for serum concentrations of haptoglobin and SAA over time in comparing the overall haptoglobin and SAA responses in the challenges with 100 and $1000 \mathrm{ng}$ LPS/kg. This comparison was done by linear regression, and assumptions were verified on residual plots and tested for normality.

Figure 1 showing the overall changes in haptoglobin, SAA, and albumin concentrations and Figure 6 showing the ratio between haptoglobin and SAA concentrations are based on least squares means estimates obtained in the statistical analysis, whereas Figures 2 to 4 show raw data.

\section{RESULTS}

All cows developed clinical, hematological, and blood biochemical signs of endotoxicosis in response to the 3 challenges. The response to LPS was characterized by depression, anorexia, hyperthermia, tachypnoea, tachycardia, ruminal hypomotility, diarrhea, and leukopenia followed by leukocytosis, thrombocytopenia, hypocalcemia, hypoferremia, and hypozincemia followed by a short hyperzincemia. The clinical signs of endotoxicosis commenced within 30 min after LPS injection, and many of the responses persisted for several days. After the challenge with 100 and $1000 \mathrm{ng}$ LPS/ $\mathrm{kg}$, the cows experienced a complete ruminal stasis of a short duration after which the ruminal motility returned to preinjection levels within 24 to $36 \mathrm{~h}$. Rectal temperature peaked in mono-, bi-, and triphasic patterns in challenges with 10, 100, and $1000 \mathrm{ng} \mathrm{LPS} / \mathrm{kg}$, respectively. Leukopenia, but no significant leukocytosis, developed in response to the challenge with $10 \mathrm{ng}$ LPS/kg; significant leukopenia and leukocytosis both developed after the challenges with the 2 highest LPS doses. Peak leukocyte levels were $8.4 \times 10^{9} / \mathrm{L}, 12.2 \times$ $10^{9} / \mathrm{L}$, and $14.1 \times 10^{9} / \mathrm{L}$ after the challenge with 10,100 , and $1000 \mathrm{ng} \mathrm{LPS} / \mathrm{kg}$, respectively.

Serum concentrations of haptoglobin and SAA increased significantly above the prechallenge baseline levels in all 3 challenges (Table 1, Figure 1) and differed among cows (Figures 2, 3, and 4). In all 3 challenges, SAA concentrations peaked and fell towards the prechallenge levels quicker than haptoglobin concentrations (Table 1, Figure 1).

Albumin concentrations decreased significantly below the prechallenge baseline levels in all 3 challenges (Table 1, Figure 1). The decrease was biphasic with an acute drop lasting for $6 \mathrm{~h}$ followed by a return to baseline and eventually a more pronounced decrease that lasted for several days (Table 1, Figure 1). The preinjection serum concentration of albumin was significantly lower in the challenge with $1000 \mathrm{ng}$ LPS/kg than in the other 2 challenges (Table 2, Figure 1).

The APP responses were dose dependent, and the effects of LPS dose and sampling time were interdependent (Table 3), showing that the dose dependency changed over the course of the challenges. The dosedependent increase in haptoglobin and SAA concentrations relied almost exclusively on differences between the challenges with 10 and $100 \mathrm{ng}$ LPS/kg; only the SAA concentrations differed significantly between the challenges with 100 and $1000 \mathrm{ng}$ LPS/kg (96 h after LPS injection, Table 2). The acute, short-lasting decrease 
Table 1. Duration of alterations (decrease and/or increase) in the acute phase protein concentrations after Escherichia coli LPS injection. ${ }^{1}$

\begin{tabular}{llll}
\hline & $10 \mathrm{ng}$ LPS/kg & $100 \mathrm{ng} \mathrm{LPS} / \mathrm{kg}$ & $1000 \mathrm{ng} \mathrm{LPS} / \mathrm{kg}$ \\
\hline Serum amyloid A & 12 to 36 & 6 to 72,144 & 12 to 96,144 \\
Haptoglobin & 36 to 48 & 36 to 96 & 36 to 144 \\
Albumin & $0.5,2,5$ to 6,36 to 48 & 1 to 6,36 to 120 & 1 to $6,36,72$ to 96 \\
\hline
\end{tabular}

\begin{abstract}
${ }^{1}$ Numbers are time intervals (h) when concentrations of acute phase proteins were significantly different $(P<0.05)$ from the prechallenge concentrations. Eight cows were challenged 3 times each by intravenous injection of increasing doses (10,100, and $1000 \mathrm{ng} / \mathrm{kg}$, consecutively) of Escherichia coli LPS, with 3-wk intervals. In each challenge, LPS was injected intravenously at $0 \mathrm{~h}$. Refer to Figure 1 for comparison with the course of the acute phase protein responses in the 3 challenges.
\end{abstract}

in albumin concentrations became successively more pronounced with each increase in LPS dose, whereas the magnitude of the protracted second decrease did not differ between the challenges with 100 and 1000 ng LPS/kg (Table 2). The individual cows differed significantly with respect to their serum levels of APP after each challenge (Table 3), and cow identity as an explanatory variable accounted for 21,22 , and $29 \%$ of the variation in SAA, haptoglobin, and albumin concentrations, respectively (Table 3). Cumulative SAA concentrations (measured by AUC) after the challenge with $100 \mathrm{ng}$ LPS/kg had a positive linear correlation with those resulting from the challenge with $1000 \mathrm{ng}$ LPS/ $\mathrm{kg}\left(P<0.01, \mathrm{r}^{2}=0.91\right)$, and haptoglobin concentrations in these 2 challenges had a tendency for a positive linear correlation $\left(P=0.057, \mathrm{r}^{2}=0.48\right)$ (Figure 5). The levels of haptoglobin and SAA (measured by AUC) did not correlate in any of the challenges $(P=0.27$ and 0.87 for the challenge with 100 and the challenge with 1000 ng LPS/kg, respectively).

The ratio between haptoglobin and SAA concentrations did not depend on LPS dose or individual $(P>$ 0.05), but depended significantly on sampling time after the challenge $(P<0.02)$ and increased with increasing time relative to the injection of LPS (Figure 6).

\section{DISCUSSION}

All 3 LPS doses induced clinical signs, significant increases in SAA and haptoglobin concentrations, and significant decreases in albumin concentrations in all cows (Table 1). This is the first study to show induction of an acute phase response by an intravenous LPS dose of $10 \mathrm{ng} / \mathrm{kg}$, and this finding confirms that cattle are highly sensitive to LPS (Berczi et al., 1966). Very few studies on ruminant endotoxicosis have used LPS doses as low as those employed in the present study (Eades, 1993; Andersen, 1994). However, low-dose LPS challenges are probably relevant in studies aimed at mimicking the acute phase response elicited during the course of naturally occurring LPS-associated diseases. In cows with severe coliform mastitis and experimen- tally induced ruminal acidosis, LPS was detected in the systemic circulation in amounts roughly corresponding to those resulting from the doses used in the present study (Katholm and Andersen, 1992; Andersen et al., 1994).

The serum concentrations of SAA and haptoglobin started to increase within 6 and $36 \mathrm{~h}$ after the challenge, respectively, and concentrations remained elevated for up to $144 \mathrm{~h}$. In contrast, albumin is a negative APP, the serum concentrations of which decrease during the acute phase response. After all 3 intravenous LPS challenges, the albumin concentrations decreased in a biphasic manner (Figure 1). The first decrease occurred between 1 and $6 \mathrm{~h}$ after LPS injection and was probably a result of an inflammation-induced increase in vascular permeability that allowed efflux of serum proteins to the perivascular tissue. The second decrease, which occurred from $36 \mathrm{~h}$ postchallenge onwards, was probably a reflection of decreased hepatic albumin synthesis resulting from a cytokine-induced reduction in gene transcription (Aldred and Schreiber, 1993). Albumin levels normalized within the observation period of each challenge. Nevertheless, the prechallenge levels of albumin became progressively reduced over the experimental period, and prior to the challenge with $1000 \mathrm{ng}$ LPS $/ \mathrm{kg}$, the concentration of albumin was significantly lower than the prechallenge levels in the 2 previous challenges. The reasons for this finding could not be determined, but might be related to the slow turnover of albumin in cattle.

The APP responses were dose dependent (Table 2). The responses of SAA, haptoglobin, and albumin were markedly increased when the LPS dose was increased from 10 to $100 \mathrm{ng} / \mathrm{kg}$, whereas the challenge with 1000 ng LPS/kg resulted in APP responses of a similar magnitude as those seen after the challenge with $100 \mathrm{ng}$ LPS/kg. It therefore seems that the APP synthesizing capacity of the liver had been reached already at the second challenge. This may reflect limitations in cytokine secretory capacity, as described by Gerros et al. (1993). In this study, serum concentrations of interleukin-1 and $\mathrm{TNF} \alpha$ in calves did not reflect the LPS dose 

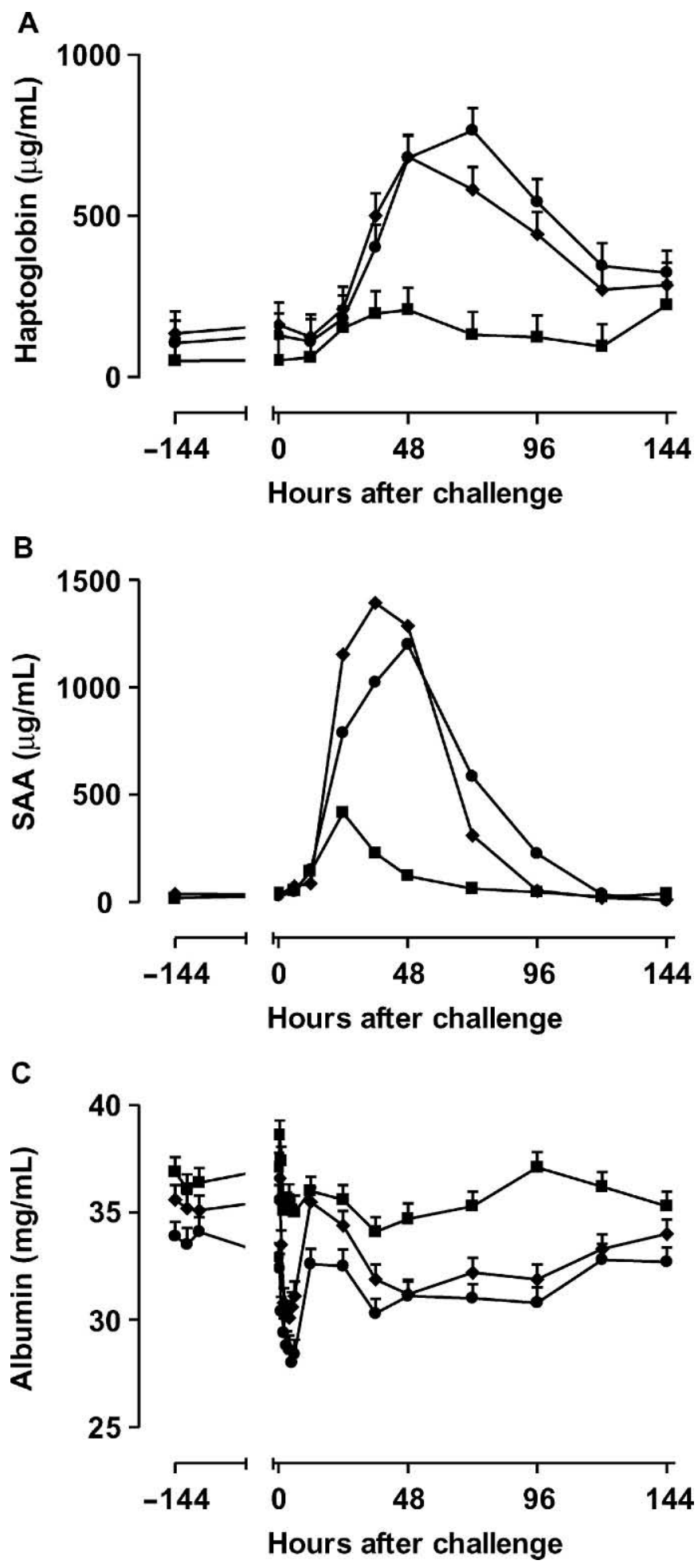

Figure 1. Estimates of LSM $( \pm$ SEM) of haptoglobin $(A)$, serum amyloid A (SAA) (B), and albumin (C) concentrations in 8 dairy cows challenged by intravenous injection of $10 \mathrm{ng}(\boldsymbol{\square}), 100 \mathrm{ng}(\bullet)$, and $1000 \mathrm{ng}$ ( ) O55:B5 Escherichia coli LPS/kg, consecutively.
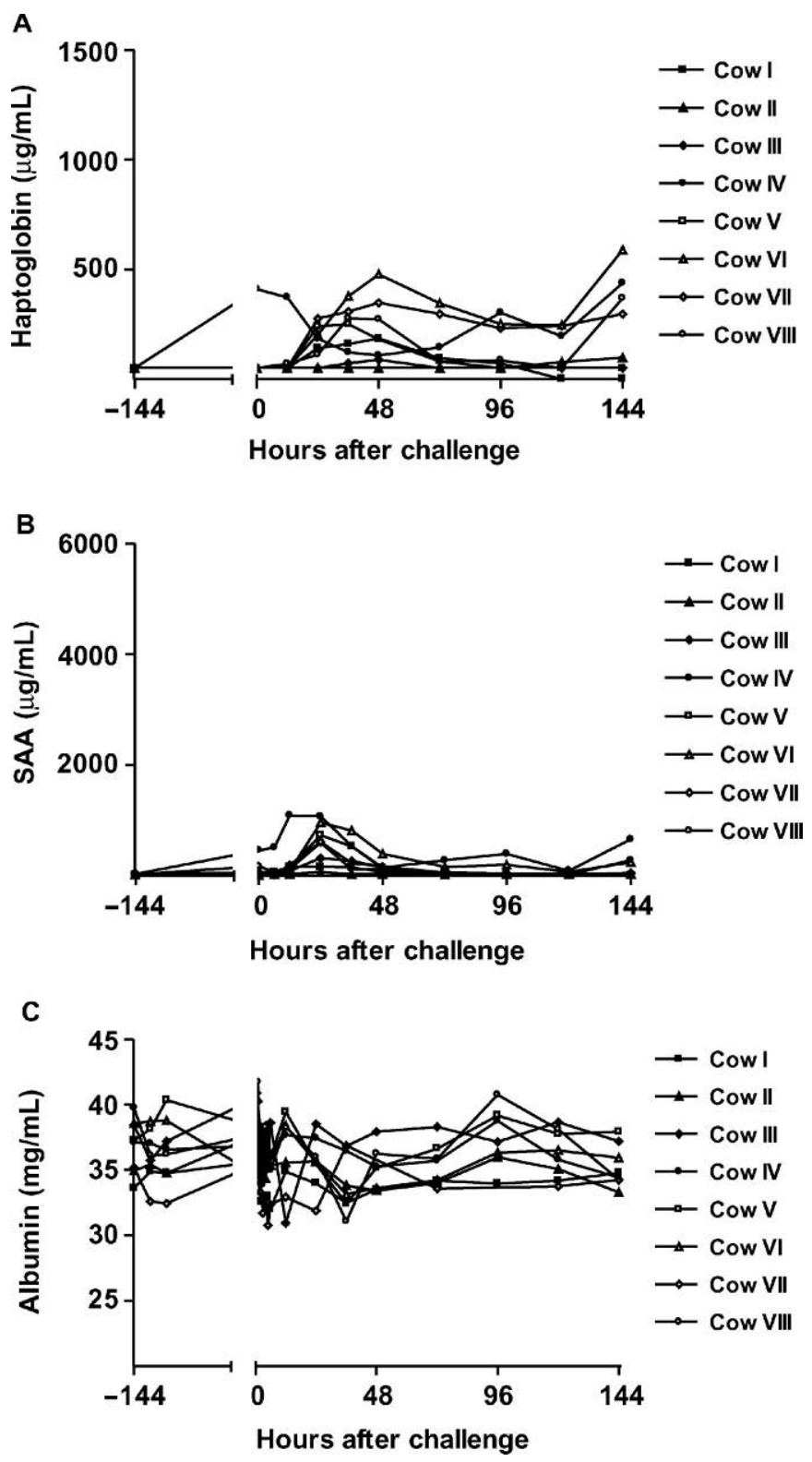

Figure 2. Individual haptoglobin (A), serum amyloid A (SAA) (B), and albumin $(\mathrm{C})$ responses in 8 dairy cows challenged by intravenous injection of $10 \mathrm{ng} / \mathrm{kg}$ LPS (Escherichia coli O55:B5).

infused intravenously, and the authors suggested that cytokine secretion might be subject to a threshold effect and that the already-lowest LPS dose $(200 \mathrm{ng} / \mathrm{kg}) \mathrm{had}$ resulted in near maximal cytokine synthesis. It may also rely on the fact that the homeostatic changes in the liver during the acute phase response can only proceed to a certain extent, thus limiting the repartitioning of amino acids from albumin to APP synthesis. The results of the present study support this by demonstrating that both challenges with 100 and with $1000 \mathrm{ng}$ 
A

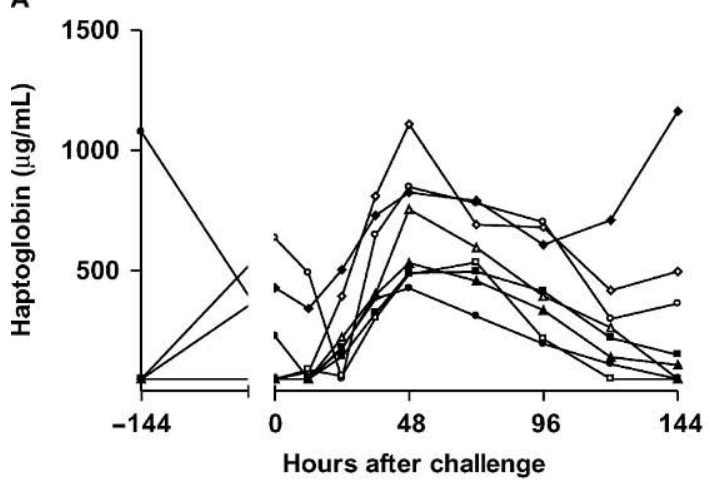

B

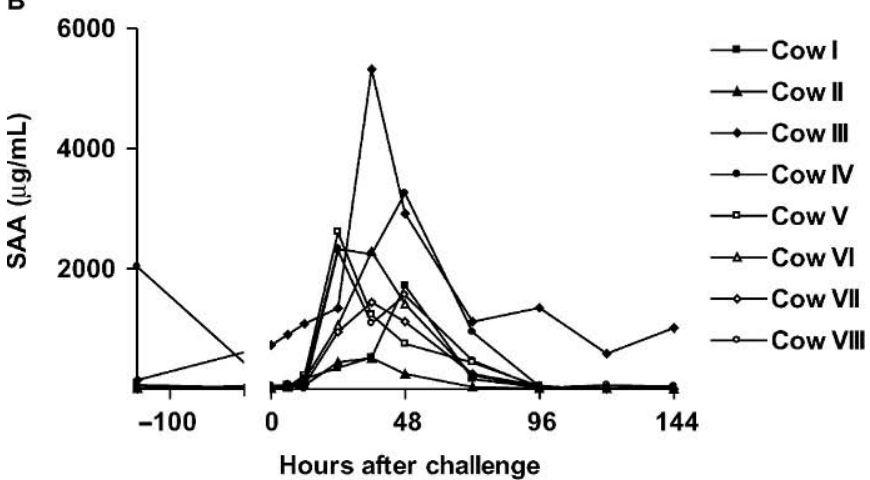

C

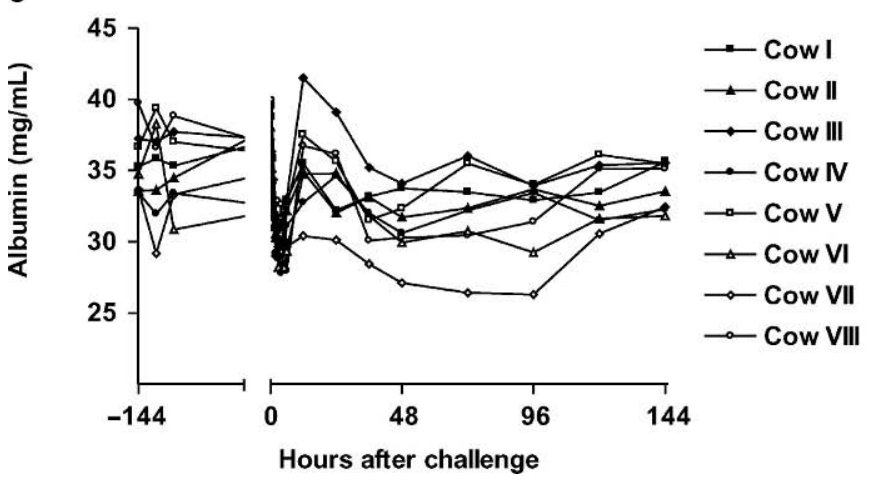

Figure 3. Individual haptoglobin (A), serum amyloid A (SAA) (B), and albumin $(\mathrm{C})$ responses in 8 dairy cows challenged by intravenous injection of $100 \mathrm{ng} / \mathrm{kg}$ LPS (Escherichia coli O55:B5).

LPS/kg seemed to induce equal levels of hypoalbuminemia.

The minimal differences in APP responses after the challenge with 100 and challenge with $1000 \mathrm{ng}$ LPS/ kg might also be explained by induction of LPS tolerance. It is widely acknowledged that repeated or continuous exposure to LPS leads to a state of hyporesponsiveness characterized by marked reduction in the magnitude and/or duration of LPS responses such as hyperthermia, anorexia, circulatory changes, and ruminal hypomotility. However, we believe that in the pres-
A

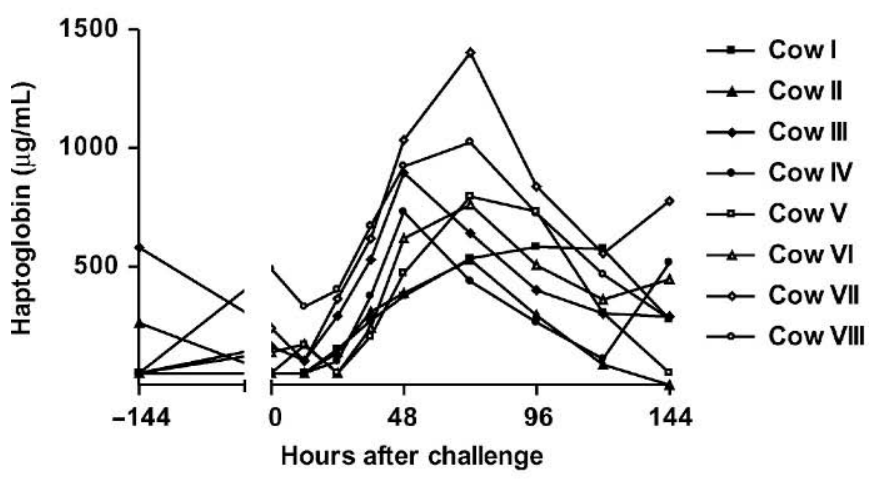

B

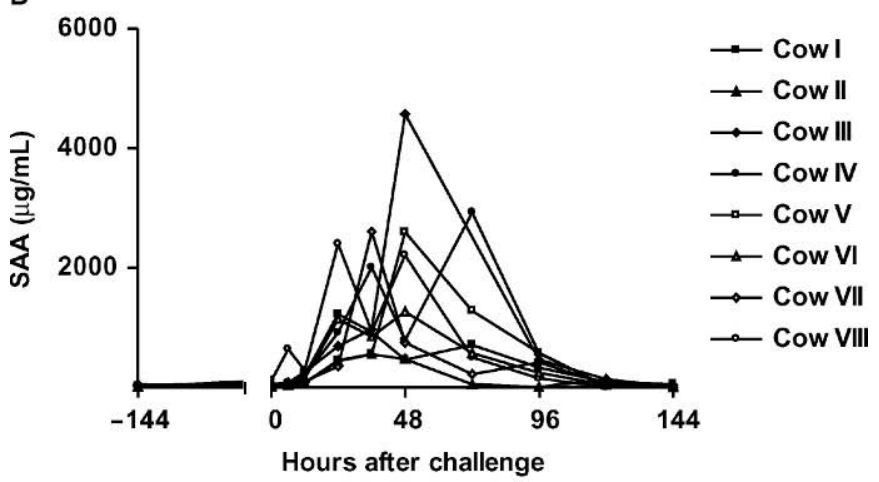

C

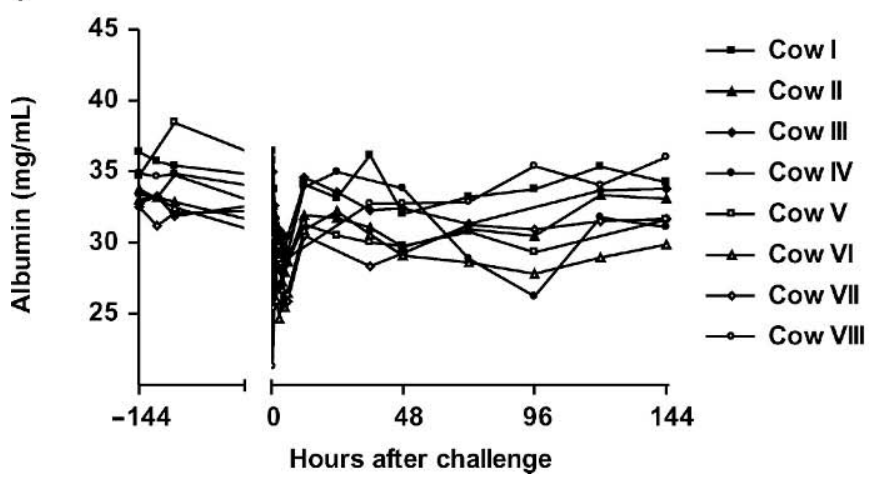

Figure 4. Individual haptoglobin (A), serum amyloid A (SAA) (B), and albumin (C) responses in 8 dairy cows challenged by intravenous injection of $1000 \mathrm{ng} / \mathrm{kg}$ LPS (Escherichia coli O55:B5).

ent study the cows were not rendered clinically tolerant towards the effects of LPS. First, clinical tolerance has been reported to peak 3 to $4 \mathrm{~d}$ after LPS exposure and then wane gradually, leaving the animals fully susceptible at approximately 7 to $21 \mathrm{~d}$ after the first LPS exposure (Beeson, 1947; Sanchez-Cantu et al., 1989), a feature that the present study was designed to take into account by spacing the LPS injections 3 wk apart. Second, the LPS used in the present study was prepared by Westphal's extraction. This method ensures a highly purified compound, which exhibits poor antigenicity 
Table 2. Dose dependency of acute phase protein responses after Escherichia coli LPS injection. ${ }^{1}$

\begin{tabular}{llll}
\hline & 10 vs. $100 \mathrm{ng} \mathrm{LPS} / \mathrm{kg}$ & 100 vs. $1000 \mathrm{ng} \mathrm{LPS} / \mathrm{kg}$ & 10 vs. $1000 \mathrm{ng} \mathrm{LPS} / \mathrm{kg}$ \\
\hline Serum amyloid A & 36 to 72,144 & 96 & 36 to 96,144 \\
Haptoglobin & 36 to 96 & - & 36 to 120 \\
Albumin & 0.5 to 6,36 to 120 & 0 to 1,5 to 12 & -144 to 144 \\
\hline
\end{tabular}

\begin{abstract}
${ }^{1}$ Numbers are time intervals $(\mathrm{h})$ when concentrations of acute phase proteins differed significantly $(P<$ 0.05) between challenge with 10, 100, and $1000 \mathrm{ng}$ Escherichia coli LPS/kg. Eight cows were challenged 3 times each by intravenous injection of increasing doses (10,100, and $1000 \mathrm{ng} / \mathrm{kg}$, consecutively) of Escherichia coli LPS with 3 -wk intervals. In each challenge, LPS was injected intravenously at $0 \mathrm{~h}$. Refer to Figure 1 for comparison with the course of the acute-phase protein responses in the 3 challenges.
\end{abstract}

and hence induces minimal antibody-dependent tolerance (Greisman et al., 1969). Third, most of the clinical, hematological, and blood biochemical responses of the cows showed unambiguous dose-response relationships (Jacobsen et al., accepted).

Concentrations of APP have been shown to reflect the extent of underlying tissue damage and are thus often used as indicators of disease severity (Deignan et al., 2000; Heegaard et al., 2000). However, by showing that approximately one-fourth of the variation in the serum concentrations of APP could be attributed to the individual, the results of the present study demonstrate that, in addition to the dose-response relationship with LPS, the APP concentrations achieved during an acute phase response are highly dependent on the individual animal. A pronounced individual variation in the clinical response to Gram-negative infections and LPS challenges in cattle have been described previously (Michaels et al., 1988; Hirvonen et al., 1999), but this is the first study to evaluate individual variation in the APP response to LPS. Some previous studies have also failed to demonstrate a clear dose-response relationship between intensity of the stimulus or extent of tissue damage and the resulting APP concentrations. For example, in cattle with respiratory tract disease, APP responses were very variable and not or only to a limited degree associated with the severity of clinical or subclinical disease, effect of treatment, or pulmonary lesions detected at slaughter (Wittum et al., 1996; Gånheim et al., 2003). The individual variation in APP response to LPS may be related both to the genotype of the cow and to the metabolism and disease status of the cow, as hepatic protein synthesizing capacity may be influenced by a number of pathological conditions or physiological states. By demonstrating that the individual APP responses in 2 consecutive challenges were quantitatively similar (Figure 5), the results of the present study suggest that some cows may have an innately higher APP response than others.

The significance of the individual differences in the APP response remains to be elucidated. Serum amyloid A and haptoglobin have been suggested to play important roles in modulation of the inflammatory response (Linke et al., 1991; Rossbacher et al., 1999; Badolato et al., 2000), and the ability to synthesize APP may thus play a role in the ability of the cow to withstand harmful effects of an inflammatory insult. Acute phase proteins have previously been shown to protect mice against a lethal challenge of Gram-negative bacteria or LPS (Alcorn et al., 1992; Vogels et al., 1993), suggesting that an appropriately orchestrated acute phase response could be involved in determining the outcome of LPS-mediated disease.

In cattle, SAA is generally perceived as an indicator of acute inflammation, whereas haptoglobin is more slowly reacting and thus reflects the presence of chronic inflammatory conditions (Alsemgeest et al., 1994; Horadagoda et al., 1999). This relationship has been demon-

Table 3. Significance of effects of time, LPS dose, individual, and the interaction between time and LPS dose on acute phase protein responses to LPS, and percentage of variation accounted for by the individual.

\begin{tabular}{|c|c|c|c|c|c|}
\hline \multirow[b]{2}{*}{ Response variable } & \multicolumn{4}{|c|}{$P$ values } & \multirow{2}{*}{$\begin{array}{l}\text { Variation } \\
\text { accounted for by } \\
\text { the individual }^{1}\end{array}$} \\
\hline & Time $(\mathrm{h})$ & LPS dose & Individual & Time $\times$ dose & \\
\hline Serum amyloid A & $<0.001$ & 0.090 & $<0.01$ & $<0.001$ & $21 \%$ \\
\hline Haptoglobin & $<0.001$ & $<0.01$ & $<0.05$ & $<0.001$ & $22 \%$ \\
\hline Albumin & $<0.001$ & $<0.001$ & $<0.001$ & $<0.01$ & $29 \%$ \\
\hline Haptoglobin/SAA ratio & $<0.020$ & $\mathrm{NS}^{2}$ & NS & NS & Not tested \\
\hline
\end{tabular}

${ }^{1}$ Calculated as differences in residuals between the full statistical model (with time, LPS dose, individual, and interaction between time and LPS dose as explanatory variables) and a statistical model in which individual was left out.

${ }^{2} \mathrm{NS}=$ Not significant. 


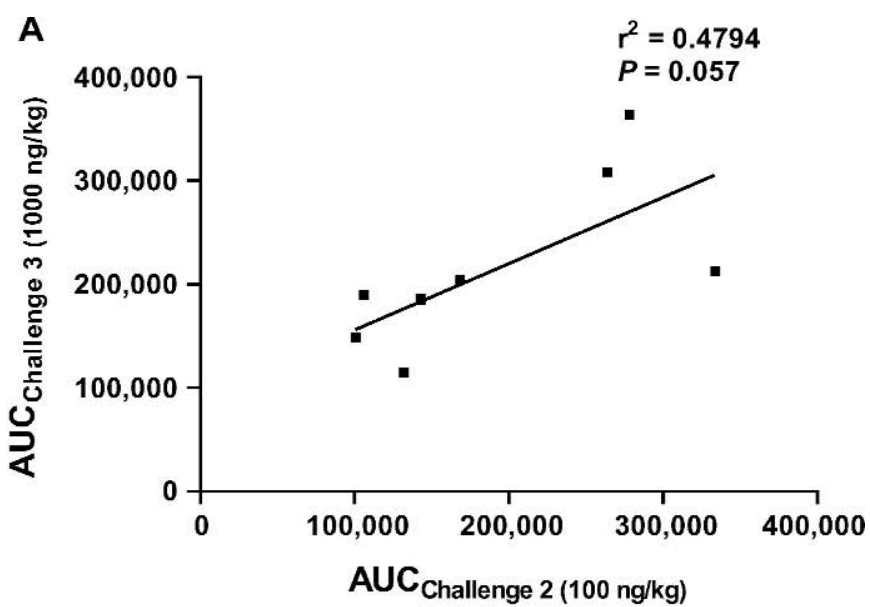

B

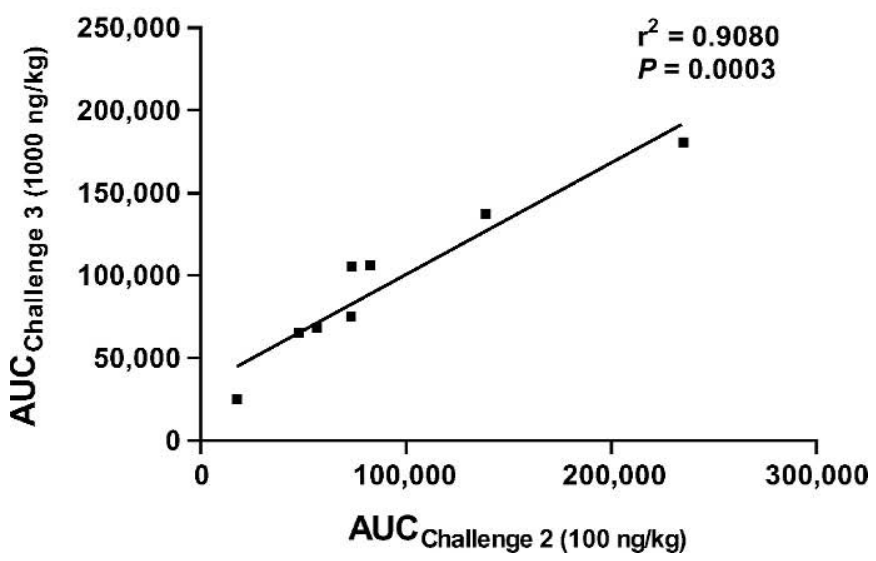

Figure 5. Comparison of cumulative haptoglobin (A) and serum amyloid A (B) production (measured by areas under the curve, AUC) in 2 consecutive intravenous challenges with LPS (Escherichia coli O55:B5). Each square represents AUC of 1 cow.

strated in experimental models involving LPS (Werling et al., 1996), bacteria (Hirvonen et al., 1999), and virus (Heegaard et al., 2000). The results of the present study concur, as SAA concentrations started to increase and peaked before haptoglobin levels, and haptoglobin levels remained elevated above the prechallenge baseline levels for a longer time than SAA (Figure 1). This resulted in an overall increase in the haptoglobin-to-SAA ratio over the course of the challenges (Figure 6). However, numerically large (yet not statistically significant) individual differences were found in the haptoglobinto-SAA ratios at each sampling time after the challenge (data not shown), indicating that care should be exercised when interpreting haptoglobin-to-SAA ratios in terms of chronicity and thus likelihood of successful treatment of disease as suggested previously (Gruys et al., 1993). A recent study on experimentally induced acute and chronic Staphylococcus aureus mastitis dem-

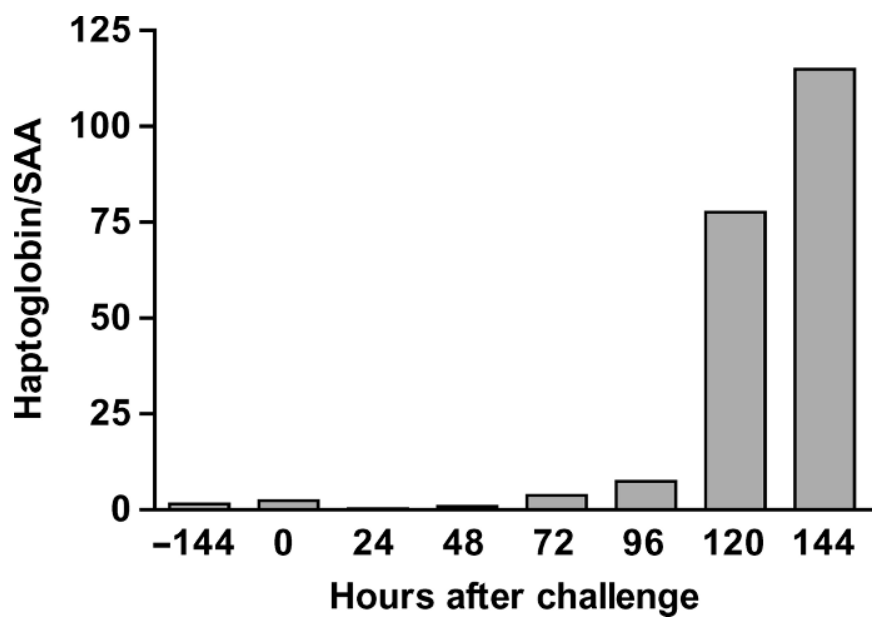

Figure 6. Haptoglobin-to-serum amyloid A (SAA) ratios at different times after intravenous injection of LPS (Escherichia coli O55:B5). Data were summarized across challenges. Where SAA and haptoglobin concentrations were immeasurable, the detection limits of the tests $(0.3$ and $50 \mu \mathrm{g} / \mathrm{mL}$, respectively) were used for calculating ratios between concentrations.

onstrated that SAA and haptoglobin responses had similar time courses (Grönlund et al., 2003), and SAA and haptoglobin profiles may thus differ between different types of infection or inflammation.

In contrast to what has been shown previously in calves inoculated with bovine respiratory syncytial virus (Heegaard et al., 2000), a large SAA response in an individual cow was not correlated with a large haptoglobin response in the same cow. This indicates that SAA and haptoglobin synthesis in response to LPS are regulated in different ways in the bovine. The ideal cytokine combinations for induction of SAA and haptoglobin have been investigated in bovine hepatocyte cultures. Alsemgeest et al. (1996) showed that SAA synthesis could be induced by either of the cytokines IL- 6 and $\mathrm{TNF} \alpha$, whereas a combination of both was required for haptoglobin to be synthesized. Steroid hormones such as dexamethasone or cortisol have also been shown to induce or have a permissive effect on haptoglobin synthesis in bovine hepatocytes (Higuchi et al., 1994; Alsemgeest et al., 1996). Given the complexity of the cytokine network, it is very likely that the cytokine combination optimal for SAA synthesis in vivo is different from the combination inducing maximal haptoglobin synthesis.

\section{CONCLUSION}

In conclusion, the results of the present study show that even very low levels of LPS induce an APP response. The levels of SAA, haptoglobin, and albumin were dependent on both the dose of LPS and the individ- 
ual cow, and approximately one-fourth of the variation in APP concentrations could be attributed to the individual. A cautious interpretation of APP levels may thus be warranted when APP are used as indicators of the extent of pathology or effect of therapy. Sequential measurements in the same animal may be necessary to accurately assess the disease status. Moreover, the results suggest that the ability to mount an APP response is an innate characteristic and will occur to the same extent in the individual cow challenged repeatedly.

\section{ACKNOWLEDGMENTS}

Associate professor, A. K. Ersbøll, Royal Veterinary and Agricultural University, Denmark is thanked for her invaluable help with the statistical model, and laboratory technician T. Petersen, Danish Veterinary Institute, Denmark for performing the haptoglobin analyses.

\section{REFERENCES}

Alcorn, J. M., J. Fierer, and M. Chojkier. 1992. The acute-phase response protects mice from D-galactosamine sensitization to endotoxin and tumor necrosis factor- $\alpha$. Hepatology 15:122-129.

Aldred, A. R., and G. Schreiber. 1993. The negative acute phase proteins. Pages 21-37 in Acute phase proteins. Molecular biology, biochemistry, and clinical applications. A. Mackiewich, I. Kushner, and H. Baumann, ed. CRC Press, Boca Raton, FL.

Alsemgeest, S. P. M., H. C. Kalsbeek, Th. Wensing, J. P. Koeman, A. M. van Ederen, and E. Gruys. 1994. Concentrations of serum amyloid A (SAA) and haptoglobin ( $\mathrm{Hp})$ as parameters of inflammatory diseases in cattle. Vet. Q. 16:21-23.

Alsemgeest, S. P. M., G. A. E. van't Klooster, A. S. J. P. A. M. van Miert, C. K. Hulskamp-Koch, and E. Gruys. 1996. Primary bovine hepatocytes in the study of cytokine induced acute-phase protein secretion in vitro. Vet. Immunol. Immunopathol. 53:179-184.

Andersen, P. H. 1994. Portal infusion of low-dosage endotoxin: A model simulating translocation of ruminal endotoxin in cattle. Acta Vet. Scand. 35:111-114.

Andersen, P. H., M. Hesselholt, and N. Jarløv. 1994. Endotoxin and arachidonic acid metabolites in portal, hepatic and arterial blood of cattle with acute ruminal acidosis. Acta Vet. Scand. 35:223243.

Araujo, L. M. M., O. G. Ribeiro, M. Siqueira, M. De Franco, N. Starobinas, S. Massa, W. H. K. Cabrera, D. Mouton, M. Seman, and O. M. Ibañez. 1998. Innate resistance to infection by intracellular bacterial pathogens differs in mice selected for maximal or minimal acute inflammatory response. Eur. J. Immunol. 28:29132920.

Badolato, R., J. M. Wang, S.-L. Stornello, A. Negro Ponzi, M. Duse, and T. Musso. 2000. Serum amyloid A is an activator of PMN antimicrobial functions: Induction of degranulation, phagocytosis, and enhancement of anti-Candida activity. J. Leukocyte Biol. 67:381-386.

Beeson, P. B. 1947. Tolerance to bacterial pyrogens. I. Factors influencing its development. J. Exp. Med. 86:29-44.

Berczi, I., L. Bertók, and T. Bereznai. 1966. Comparative studies on the toxicity of Escherichia coli lipopolysaccharide endotoxin in various species. Can. J. Microbiol. 12:1070-1071.

Blum, J. W., H. Dosogne, D. Hoeben, F. Vangroenweghe, H. M. Hammon, R. M. Bruckmaier, and C. Burvenich. 2000. Tumor necrosis factor- $\alpha$ and nitrite/nitrate responses during acute mastitis in- duced by Escherichia coli infection and endotoxin in dairy cows. Dom. Anim. Endocrinol. 19:223-235.

Boosman, R., C. W. A. A. Mutsaers, and A. Klarenbeek. 1991. The role of endotoxin in the pathogenesis of acute bovine laminitis. Vet. Q. 13:155-162.

Boosman, R., Th. A. Niewold, C. W. A. A. Mutsaers, and E. Gruys. 1989. Serum amyloid A concentrations in cows given endotoxin as an acute-phase stimulant. Am. J. Vet. Res. 50:1690-1694.

Deignan, T., A. Alwan, J. Kelly, J. McNair, T. Warren, and C. O'Farrelly. 2000. Serum haptoglobin: An objective indicator of experimentally-induced Salmonella infection in calves. Res. Vet. Sci. 69:153-158.

Eades, S. C. 1993. Endotoxemia in dairy cattle: Role of eicosanoids in reticulorumen stasis. J. Dairy Sci. 76:414-420.

Gånheim, C., C. Hultén, U. Carlsson, H. Kindahl, R. Niskanen, and K. P. Waller. 2003. The acute phase response in calves experimentally infected with bovine viral diarrhea virus and/or Mannheimia haemolytica. J. Vet. Med. B 50:183-190.

Gerros, T. C., S. D. Semrad, R. A. Proctor, and A. LaBorde. 1993. Effect of dose and method of administration of endotoxin on cell mediator release in neonatal calves. Am. J. Vet. Res. 54:21212127.

Godson, D. L., M. Campos, S. K. Attah-Poku, M. J. Redmond, D. M. Cordeiro, M. S. Sethi, R. J. Harland, and L. A. Babiuk. 1996. Serum haptoglobin as an indicator of the acute phase response in bovine respiratory disease. Vet. Immunol. Immunopathol. $51: 277-292$.

Greisman, S. E., E. J. Young, and F. A. Carozza. 1969. Mechanisms of endotoxin tolerance. V. Specificity of the early and late phases of pyrogenic tolerance. J. Immunol. 103:1223-1236.

Grönlund, U., C. Hultén, P. D. Eckersall, C. Hogarth, and K. P. Waller. 2003. Haptoglobin and serum amyloid A in milk and serum during acute and chronic experimentally induced Staphylococcus aureus mastitis. J. Dairy Res. 70:379-386.

Gruys, E., A. M. van Ederen, S. P. M. Alsemgeest, H. C. Kalsbeek, and Th. Wensing. 1993. Acute phase protein values in blood of cattle as indicator of animals with pathological processes. Arch. Lebensmittelhyg. 44:107-111.

Heegaard, P. M. H., D. L. Godson, M. J. M. Toussaint, K. Tjørnehøj, L. E. Larsen, B. Viuff, and L. Rønsholt. 2000. The acute phase response of haptoglobin and serum amyloid A (SAA) in cattle undergoing experimental infection with bovine respiratory syncytial virus. Vet. Immunol. Immunopathol. 77:151-159.

Higuchi, H., N. Katoh, T. Miyamoto, E. Uchida, A. Yuasa, and K. Takahashi. 1994. Dexamethasone-induced haptoglobin release by calf liver parenchymal cells. Am. J. Vet. Res. 55:1080-1085.

Hirvonen, J., K. Eklund, A. M. Teppo, Gy. Huszenicza, M. Kulcsár, H. Saloniemi, and S. Pyörälä. 1999. Acute phase response in dairy cows with experimentally induced Escherichia coli mastitis. Acta Vet. Scand. 40:35-46.

Horadagoda, N. U., K. M. G. Knox, H. A. Gibbs, S. W. J. Reid, A. Horadagoda, S. E. R. Edwards, and P. D. Eckersall. 1999. Acute phase proteins in cattle: Discrimination between acute and chronic inflammation. Vet. Rec. 144:437-441.

Jacobson, S., T. Toelboell, and P. H. Andersen. Dose dependency and individual variability in selected clinical, hematological, and blood biochemical responses after systemic lipopolysaccharide challenge in cattle. Vet. Res. (accepted).

Katholm, J., and P. H. Andersen. 1992. Acute coliform mastitis in dairy cows: Endotoxin and biochemical changes in plasma and colony-forming units in milk. Vet. Rec. 131:513-514.

Linke, R. P., V. Bock, G. Valet, and G. Rothe. 1991. Inhibition of the oxidative burst response of $\mathrm{N}$-formyl peptide stimulated neutrophils by serum amyloid A. Biochem. Biophys. Res. Commun. 176:1100-1105.

Lohuis, J. A. C. M., Y. H. Schukken, P. A. J. Henricks, R. Heyneman, C. Burvenich, J. H. M. Verheijden, and A. S. J. P. A. M. van Miert. 1990. Preinfection functions of blood polymorhonuclear leukocytes and the outcome of experimental Escherichia coli mastitis in the cow. J. Dairy Sci. 73:342-350. 
McDonald, T. L., A. Weber, and J. W. Smith. 1991. A monoclonal antibody sandwich immunoassay for serum amyloid A (SAA) protein. J. Immunol. Methods 144:149-155.

Michaels, F. H., and K. L. Banks. 1988. Contribution of various host factors to resistance to experimentally induced bacterial endotoxemia in calves. Am. J. Vet. Res. 49:557-562.

Rossbacher, J., L. Wagner, and M. S. Pasternack. 1999. Inhibitory effect of haptoglobin on granulocyte chemotaxis, phagocytosis and bactericidal activity. Scand. J. Immunol. 50:399-404.

Sanchez-Cantu, L., H. N. Rode, and N. V. Christou. 1989. Endotoxin tolerance is associated with reduced secretion of tumor necrosis factor. Arch. Surg. 124:1432-1436.

SAS User's Guide. 1999. Version 8.02, Edition. SAS Inst., Inc., Cary, NC.

Sordillo, L. M., and J. E. Peel. 1992. Effect of interferon- $\gamma$ on the production of tumor necrosis factor during acute Escherichia coli mastitis. J. Dairy Sci. 75:2119-2125.
Vandeputte-van Messom, G., C. Burvenich, E. Roets, A. M. MassartLeën, R. Heyneman, W. D. J. Kremer, and A. Brand. 1993. Classification of newly calved cows into moderate and severe responders to experimentally induced Escherichia coli mastitis. J. Dairy Res. 60:19-29.

Vogels, M. T. E., L. Cantoni, M. Carelli, M. Sironi, P. Ghezzi, and J. W. M. van der Meer. 1993. Role of acute-phase proteins in interleukin-1-induced nonspecific resistance to bacterial infections in mice. Antimicr. Agents Chemother. 37:2527-2533.

Werling, D., F. Sutter, M. Arnold, G. Kun, P. C. J. Tooten, E. Gruys, M. Kreuzer, and W. Langhans. 1996. Characterisation of the acute phase response of heifers to a prolonged low dose infusion of lipopolysaccharide. Res. Vet. Sci. 61:252-257.

Wittum, T. E., C. R. Young, L. H. Stanker, D. D. Griffin, L. J. Perino, and E. T. Littledike. 1996. Haptoglobin response to clinical respiratory tract disease in feedlot cattle. Am. J. Vet. Res. 57:646-649. 